\title{
MRI of the spinal tuberculoma, paravertebral tubercular abscess and pulmonary tuberculosis
}

\author{
Rakesh Lalla, Maneesh Kumar Singh, Tushar B Patil, Neeraj Kumar
}

Department of Neurology, King George Medical University, Lucknow, Uttar Pradesh, India

\section{Correspondence to}

Professor Maneesh Kumar Singh,

maneesh_singh@rediffmail. com

\section{DESCRIPTION}

A young man presented with acute onset sensorimotor paraparesis with urinary retention 4 days prior to admission. He was reporting of fever, cough and weight loss since 2 months. A MRI of the spine revealed isointense lesion at the level of D11-12 vertebra on T1 sequence which enhances on gadolinium contrast (figure 1). T2-weighted images showed diffuse hyperintensity throughout the cord (figure 2A). The coronal short tau inversion recovery (STIR) sequence shows the presence of paraspinal collection and infiltration in the apex of left lung (figure 2B,C).

MRI is the diagnostic modality of choice for the diagnosis of spinal cord pathology. The intramedullary tuberculoma are well defined, circumscribed solitary or multiple, nodular or ring enhancing

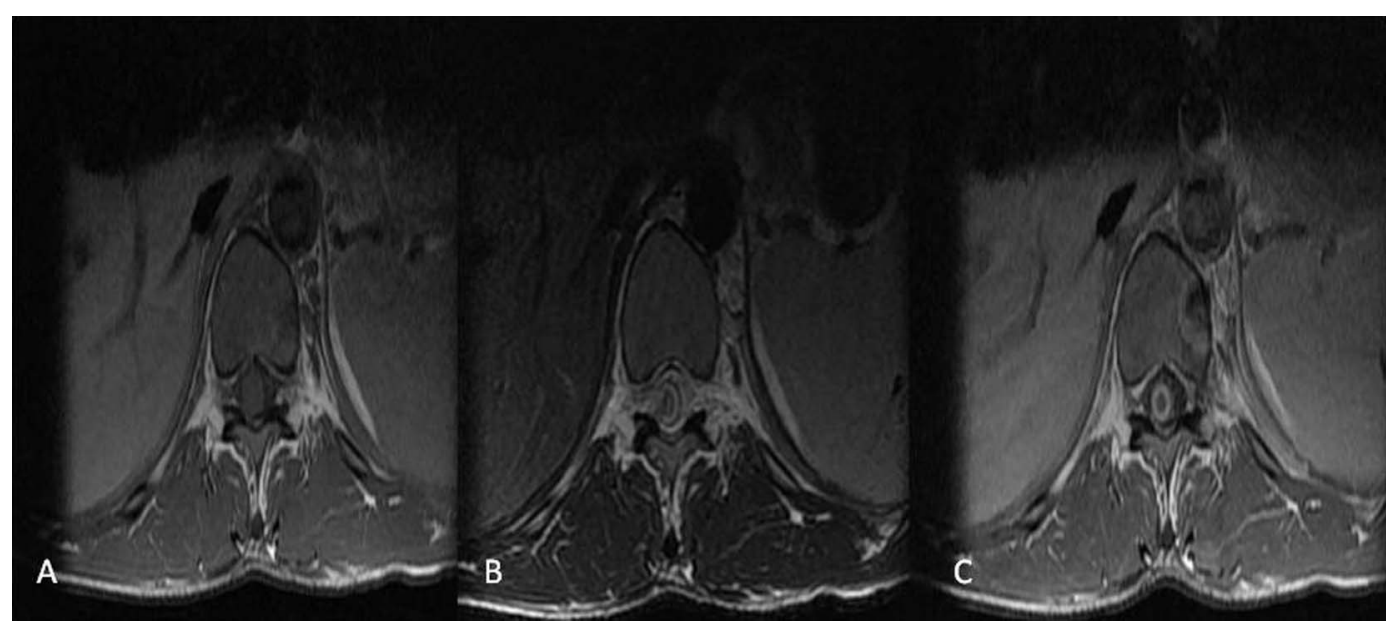

Figure 1 MRI T1-weighted (axial) at the level of D11 vertebrae in the spinal cord showing (A) isointense lesion, (B) hyperintense on $\mathrm{T} 2$ and $(\mathrm{C})$ ring enhancement on gadolinium contrast. The vertebral body also showing contrast enhancement along with paravertebral collection.

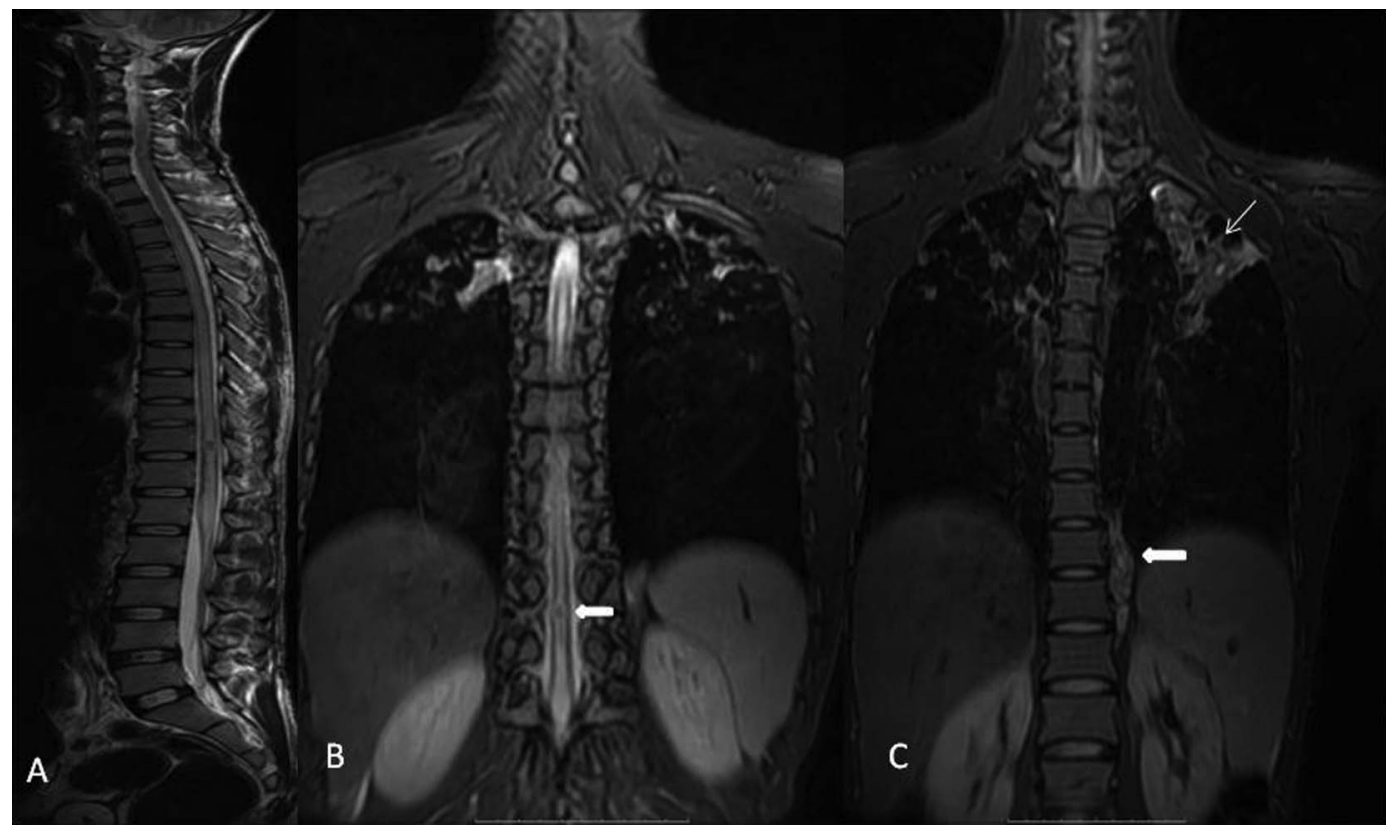

To cite: Lalla $R$, Singh MK, Patil TB, et al. BMJ Case Rep Published online: [please include Day Month Year] doi:10.1136/bcr-2013201098

Figure 2 (A) MRI T2-weighted sequence of whole spine showing diffuse hyperintense signal throughout the cord and hypointense lesion at the level of D11-12. (B) T2-weighted coronal short tau inversion recovery images showing hypointense lesion at D11-12 level and (C) showing paravertebral collection extending from D12- L3 (Bold arrow) and infiltration of left lung apex (small arrow). 
lesions (REL) with prominent cord oedema and swelling. Usually spinal tuberculosis may also have tubercular focus anywhere else in body and this greatly aids in the diagnosis of spinal tuberculoma. ${ }^{1}$ In this image we have highlighted the importance of coronal STIR sequence which identifies not only paraspinal collection but also infiltration in lung apices.

However, it is important to differentiate it from its other radiological mimics such as multiple sclerosis, abscess, neurocysticercosis and astrocytoma. The demyelinating lesions have incomplete ring enhancement and may have lesions in the brain. $^{2}$ Unlike multiple sclerosis, neuromyelitis optica presents with longitudinally extensive myelitis (lesions extending beyond 3 vertebral segments) along with optic nerve involvement. Rarely do autoimmune conditions such as systemic lupus erythematosus, sjogren syndrome mimic longitudinally extensive mye-

\section{Learning points}

MRI is the investigative method of choice for the diagnosis of spinal cord pathology.

- Short tau inversion recovery sequence is a sensitive MRI sequence for the diagnosis of soft tissue as well as bony infections.

- MRI can aid diagnosis of accompanying lesions and help to identify the disease aetiology. litis and posterior cord involvement but they also have involvement of peripheral nerves and sicca symptoms, respectively. ${ }^{3}{ }^{4}$ Intramedullary pyogenic abscess usually occurs in association with epidural abscess and shows irregular contrast uptake and cord swelling. Isolated cysticercus in the spinal cord is rare. ${ }^{1}$ The low-grade tumours show homogenous contrast uptake whereas rim enhancement is seen in anaplastic astrocytoma and glioblastoma multiforme. ${ }^{5}$ Hence accompanying lesions aid in diagnosis of spinal cord REL.

Contributors MKS formulated the hypothesis. RL, TBP and NK prepared the manuscript and images.

Competing interests None.

Patient consent Obtained.

Provenance and peer review Not commissioned; externally peer reviewed.

\section{REFERENCES}

1 DeSanto J, Ross JS. Spine infection/inflammation. Radiol Clin North Am 2011:49:105-27.

2 Klawiter EC, Benzinger T, Roy A, et al. Spinal cord ring enhancement in multiple sclerosis. Arch Neurol 2010;67:1395-8.

3 Mori K, Koike H, Misu K, et al. Spinal cord magnetic resonance imaging demonstrates sensory neuronal involvement and clinical severity in neuronopathy associated with Sjögren's syndrome. J Neurol Neurosurg Psychiatry 2001;71:488-92.

4 Lehnhardt FG, Impekoven P, Rubbert A, et al. Recurrent longitudinal myelitis as primary manifestation of SLE. Neurology 2004;63:1976.

5 Crawford JR, Zaninovic A, Santi M, et al. Primary spinal cord tumors of childhood: effects of clinical presentation, radiographic features, and pathology on survival. J Neurooncol 2009;95:259-69.

Copyright 2013 BMJ Publishing Group. All rights reserved. For permission to reuse any of this content visit http://group.bmj.com/group/rights-licensing/permissions.

BMJ Case Report Fellows may re-use this article for personal use and teaching without any further permission.

Become a Fellow of BMJ Case Reports today and you can:

- Submit as many cases as you like

- Enjoy fast sympathetic peer review and rapid publication of accepted articles

- Access all the published articles

- Re-use any of the published material for personal use and teaching without further permission

For information on Institutional Fellowships contact consortiasales@bmjgroup.com

Visit casereports.bmj.com for more articles like this and to become a Fellow 